\title{
2
}

Rafael Cano Aguilar (Sevilla)

\section{A la búsqueda de los textos olvidados. Los orígenes de la modernidad discursiva en la historia del español}

En memoria de Wulf Oesterreicher

\begin{abstract}
The transition between the seventeenth and eighteenth centuries has been a period of very little, if any, knowledge for the historians of Spanish. Between the classical period of the Siglo de Oro and the beginning of modernity in the eighteenth century there was no event of interest at that time. Modern research on the history of Spanish vocabulary or texts shows that from 1675 onwards we can find forms and discursive traditions that are central in modern Spanish, while processes from earlier periods continued. In this paper we will analyze some of the most significant (non-literary) texts of those years, and try to establish their defining linguistic and discursive traits.
\end{abstract}

1 Al iniciar una nueva investigación sobre análisis de textos e historia de la lengua, el estudioso no puede sino empezar por replantear la cuestión, siempre controvertida, de las relaciones de la Historia de la Lengua, como disciplina, con el estudio histórico de la lengua literaria y de los textos en que esta ha cristalizado, así como con los textos de muy variada naturaleza con que el investigador puede, y debe, contar.

La cuestión se ha planteado en reiteradas ocasiones, hasta el punto de que constituye un motivo recurrente en todo historiador que se precie. Pero en general, casi siempre se ha hecho de forma dicotómica, binaria: lengua literaria vs. lengua no literaria. La tradición entre los estudiosos españoles, en especial los más recientes, afirma que la lengua literaria ha sido siempre la dominante en la investigación, enunciado que suele ser proferido a modo de reproche. En efecto, se recuerda que Lapesa cita, como argumento para apoyar su pretensión de estudiar en la historia del idioma también los giros y usos que no parecen tener sino una presencia individual, la consideración de Schuchardt acerca de que el lenguaje, nacido de la necesidad, tiene su cumbre en el arte (Lapesa 2000, 63). No hay, pues, que esperar al idealismo lingüístico de Vossler o Spitzer, inspirados en la filosofía, entre otros, de Croce, para considerar a la lengua literaria como la máxima expresión de los usos lingüísticos y, por tanto, la máxima acreedora del estudio y el análisis. No obstante, el fundador de la Lingüística histórica del español, Ra- 
món Menéndez Pidal, mantuvo una actitud dual frente a la cuestión: por un lado, para las épocas primitivas utilizó la documentación iliteraria, ciertamente porque se carecía de cualquier otra, pero sobre todo porque la lengua no literaria ofrecía horizontes más amplios que la de la literatura ("La literatura nos presenta el idioma, si no fijado, como suele decirse, al menos muy cohibido por la tradición letrada, y el hecho lingüístico suele aparecer bajo una sola de sus facetas, la escogida por esa tradición”, Orígenes, 8 a ed., p. 515); pero por otro, para las épocas posteriores del idioma, el recurso a los textos no literarios, básicamente los de naturaleza jurídica, disminuye de forma drástica, de forma que parece considerar entonces a la lengua literaria como más fiable para rastrear los usos lingüísticos generales, mientras que la jurídica se fosiliza y acartona (para todo esto véanse Cano 2005 y Garatea 2005). Este vaivén de lo no literario a lo literario parece, pues, seguir las distintas vicisitudes de la producción textual castellana, y priman unos u otros tipos textuales en función de la existencia, abundancia y disponibilidad respectivas en cada época. Ello, en cierto modo, continúa la tradición de las histoires de la langue francesas en las que la concentración en lo lingüístico y la atención a textos no literarios cedían ante el omnipresente dominio de la lengua literaria a medida que esta iba adquiriendo formas cada vez más elaboradas (cfr. Vàrvaro 1972/1973). Y ese vaivén, ahora en forma de preferencias de épocas y escuelas, no ha cesado en la historiografía lingüística sobre el español: de las idealizaciones de lo literario presentes en Amado Alonso (aunque con agudísimas penetraciones en los mecanismos pragmáticos de la construcción lingüística) o en los primeros estudios lapesianos sobre sintaxis histórica del español, el péndulo ha corrido hacia la desmitificación de la lengua literaria en su validez para el estudio histórico-lingüístico, incluso hacia su descalificación plena, y hacia la utilización cada vez en mayor grado de documentación no literaria, básicamente la jurídica, pero también la de otros ámbitos discursivos (de nuevo, véase Cano 2005 para estas cuestiones). En las últimas décadas esta orientación se ha vinculado con la búsqueda, a veces obsesiva, de las "huellas de la oralidad" (en expresión de Wulf Oesterreicher) en la escritura, tomando, más o menos explícitamente, la enunciación oral como la única forma "real" de la lengua, frente a la artificiosidad de la escritura, en especial la escritura literaria. Intuitivamente, la escritura no literaria suele concebirse en bloque como más próxima al lenguaje oral, al ordinario, al real, al propio de la vida común de los hablantes.

Esta visión, cuyo simplismo puede haber sido acentuado por necesidades de esta exposición, responde, como se dijo antes, realmente a una visión dicotómica, en la que se presentan dos pilares básicos, el literario y el no literario, en torno a los cuales se organizan todas las formas enunciativas posibles. Sin embargo, dos hipótesis desarrolladas en las últimas décadas por la Romanística alemana (desde Coseriu y Schlieben-Lange a Koch, Oesterreicher, Kabatek y un largo etcétera, en 
el que han de incluirse lingüistas españoles como, muy destacadamente, López Serena) pueden ayudar a desmontar la binariedad del planteamiento y a ofrecer una visión mucho más coherente, y compleja, con el funcionamiento de las lenguas, su variación y sus modificaciones. Me refiero, obviamente, a la hipótesis de las "tradiciones discursivas" y a la superación de la dicotomía oral vs. escrito por la transición gradual de la inmediatez a la distancia comunicativas, en virtud de la presencia o no de una amplia serie de parámetros. En efecto, ni lo oral como modo físico de enunciación supone un modo peculiar, propio y excluyente de la actuación lingüística, ni la escritura, aun la literaria, se deja encerrar en una sola categoría dominante. Las lenguas históricas están constituidas por (sub)sistemas variados y en variación, de los que los hablantes disponen en mayor o menor grado para sus competencias activas y pasivas. Y se realizan a través de actos de habla que se integran en tradiciones de hablar, prefiguradas, aunque no rígidas, las cuales modelan las actuaciones concretas. La lengua no es más o menos "real" en unas u otras de sus manifestaciones, sino que adquiere cuerpo en todas ellas, y cada una manifiesta sus propias formas de elaboración, sus rasgos peculiares, sus elementos constituyentes caracterizadores. El historiador dispone solo de unos pocos restos de esas actuaciones del pasado: carece de las que solo tuvieron realización física hablada, y se encuentra sometido al albur de la conservación de fragmentos de los modos de actuación lingüística escrita, conservación en mayor o menor grado o ausencia total que dependen de condiciones históricas ante las que carece de cualquier posibilidad de control; desconoce en buena parte de casos las condiciones y el entorno en que se produjeron estas actuaciones (de ahí la necesidad de "recontextualizar" los textos de que habló Wulf Oesterreicher). Esta situación trágica del historiador de la lengua (recuérdese a Labov y su mejor uso de los peores datos) se ve compensada por el hecho de que todas las tradiciones textuales, genéricas, discursivas, más o menos fragmentadas, a las que tiene acceso forman parte por igual de la lengua histórica cuyo devenir intenta desentrañar, sin que entre ellas deban establecerse jerarquías de "representatividad"1, pues todas ellas son formas y productos igualmente legítimos de la actividad lingüística. Al igual que para las lenguas coetáneas, pero con muchos más problemas, el historiador no tiene acceso a "la" lengua sino a retazos desmembrados de la actuación, a partir de los cuales puede inferir sistemas, complejos, tradiciones. Y en esa labor los retazos con que se encuentra no pertenecen

$1 \mathrm{Ni}$ tampoco, como señala Kabatek (2016, 1-17, con referencias a estudios anteriores), todas ellas en su conjunto, recopiladas en forma de corpus, pueden considerarse representativas de "toda" la lengua. 
solo a una o a otra categoría, sino a muchas, las que la historia le da y las que él puede formular.

2 Pese a esa supuesta primacía de lo literario en el estudio histórico-lingüístico del español, la atención se ha concentrado en determinadas épocas, no solo por la abundancia o excelencia de sus textos sino también, y a veces sobre todo, por su relevancia para la historia lingüística. En este sentido, parece claro que la época de orígenes, extendida hasta la primera escritura castellana del s. XIII, y los siglos XVI y XVII (los llamados, por su bondad literaria, "siglos de oro”) han atraído de forma muy mayoritaria la atención de los estudiosos: la primera por constituir la etapa de "nacimiento" del castellano; la segunda por suponer la gran revolución que originó la lengua moderna. La atención se dirigió también hacia el siglo XV, por su carácter fronterizo entre la Edad Media y la época “clásica” (otra etiqueta de origen literario) y por los llamativos rasgos de buena parte de su producción textual literaria. Y del XVIII en adelante, muchos historiadores, entre los que me he contado, han considerado que no debían ocuparse porque eso era ya la lengua moderna, territorio para los lingüistas "sincrónicos".

Ahora bien, si hay una época que los historiadores del español parecen haber ignorado especialmente durante mucho tiempo es la que se sitúa a caballo de los siglos XVII y XVIII. En realidad, con los grandes cambios (fónicos, pero también gramaticales) del español áureo supuestamente concluidos, solo hay que esperar a que el siglo de la Ilustración comience a renovar el vocabulario, renovación que en ese siglo y en el XIX vendrá sobre todo de Francia, y que desde el XIX y ya en el XX tendrá procedencia fundamentalmente anglosajona. Se ignora, pero también se descalifica: “Imitaciones serviles y hueras de Quevedo, culteranismo sin inspiración y una invasión creciente de chabacanería y vulgarismo afean el estilo en la época de Carlos II y primeros años del siglo XVIII” es el juicio que merece a Lapesa, en su Historia ${ }^{2}$, la lengua literaria de esos años; y en sus datos lingüísticos no se rastrean referencias (salvo alguna muy ocasional) de mediados del XVII o posteriores. Pero en esto los historiadores de la lengua no han estado solos: no hay ninguna referencia a esa época en las historias de la literatura de Díez Borque o Canavaggio; son mínimas las de Alborg (solo al erudito Nicolás Antonio, al historiador Antonio de Solís y a Miguel de Molinos) y Jones (Nicolás Antonio y Francisco Santos, cuya novela El arca de Noé recibe una crítica muy negativa); y la de Rico, si bien se hace eco de las revisiones de la época promovidas por

2 Referencias, de Lapesa u otros, a la lengua inmediatamente posterior (s. XVIII) pueden verse en Octavio de Toledo 2016, 58-60 (también en su introducción a Fernández Alcaide et al. 2016, 17ss.). 
historiadores, apenas contiene referencias (y las que hay también negativas) a la producción textual de la época. Ello contrasta radicalmente con lo que ocurre en la actualidad: véase, p.ej., el número especial de Criticón $(103 / 104,2008)$ dedicado a "La literatura española en tiempos de los novatores (1675-1726)" (coordinado por Alain Bègue y Jean Croizat-Viallet).

En efecto, fueron los historiadores quienes a finales de la década de los 70 del pasado siglo empezaron a mirar con nuevos ojos esa época oscura, y oscurecida, de la historia de España. En primer lugar, los historiadores de la ciencia como López Piñero (1979 y 1993), que sacaron a la luz obras y nombres de renovadores del pensamiento y la actividad científica en España, verdaderos precursores de lo que a mediados del siglo siguiente fue la tímida Ilustración española. Desde entonces, a este benemérito grupo de médicos, astrónomos, matemáticos, pero también de historiadores y eruditos, se les aplicó el nombre que con intención despectiva se había utilizado contra ellos algo después de su aparición, el de novatores: reaccionaron contra el aristotelismo y el galenismo y defendieron métodos experimentales y la recuperación del contacto con la ciencia europea. Otros historiadores, generalistas, incidieron en la renovación y recuperación incipientes de ese período, con su tímida recuperación económica, el despertar de la periferia y el planteamiento de reformas que, como tantas otras veces, no se llevaron a cabo (Kamen 1981 [1979] y 1997); igualmente, se destacaron las nuevas condiciones intelectuales que se estaban formando, para las que no habría, pues, que esperar a las reformas borbónicas (Maravall 1978; López 1996 y 1997; Mestre Sanchís 1996 y 1998; Pérez Magallón 2002).

Y han sido también varios los historiadores del español que se han adentrado en este período, superando por tanto el prejuicio "literario" tantas veces aplicado a la disciplina, pues sus fuentes han sido textos elaborados al margen de los géneros típicos de la literatura. El punto de arranque vino dado por el estudio del léxico, justamente el ámbito en que se concede al XVIII y épocas posteriores la primacía en la evolución del idioma. Continuando y ampliando la senda iniciada en su momento por Lapesa (1966/1967) y por Bustos Tovar (1981), la tesis doctoral de Âlvarez de Miranda (publicada en 1992) situó con justicia el comienzo de su estudio, y por tanto el inicio de la renovación y ampliación léxica del español, en 1680, incluyendo así, quizá por primera vez, en las historias sobre el español el reinado del último de los Austrias, Carlos II. Trabajos posteriores del mismo autor vinieron a incidir en la relevancia de las academias y tertulias para la actividad de los novatores (1993), en las condiciones generales de su época (1996), o en algún curioso texto de la época (2008). Destaca igualmente $(1996,92)$ cómo estos novatores fueron sustituyendo el latín por el español en la escritura científica, algo que ya venía ciertamente desde la época renacentista (Porcar 2012, 250s.) y que corre paralelo al definitivo destierro del latín de la actividad académica y universitaria 
española (Gutiérrez Cuadrado 1988). No obstante, ha de señalarse que también los novatores utilizaron el latín para la expresión científica, y no solo cuando la dirigían fuera de España: ello se comprueba, entre otros, en Manuel Martí, que solo utilizó el latín, o Juan Bautista Corachán, Tomás Vicente Tosca y otros, que alternaron en su obra latín y español.

No mucho después otro grupo de historiadores, encabezados por Girón Alconchel, tomó también como objeto central de sus investigaciones esta misma época, extendida o no, según los casos, al resto del XVIII y a épocas posteriores. En sus caracterizaciones de la lengua de los Siglos de Oro es patente la preocupación de Girón por este momento final del XVII (2004), así como en diversos estudios monográficos sobre concretas cuestiones de sintaxis histórica (cfr. Girón 2012, donde culmina sus estudios sobre la formación de la secuencia artículo más relativo); pero pronto el interés se vertió al análisis discursivo, aplicado a la prosa ensayística (2003b) o general (2016a), a una obra (El hombre práctico, de Gutiérrez de los Ríos, 1686) que reúne la nueva ideología del momento (2004), o al discurso historiográfico (2016b). A partir de estos análisis, postula un incremento de la hipotaxis como forma dominante de organización discursiva (incremento, además, de la subordinación "fuerte"); junto a ello, una disminución en el uso de los marcadores discursivos no conectores, y un aumento de los conectores, con empleo no solo de conjunciones sino también de formas específicas de conexión. Todo ello supone, según sus palabras, un "descenso considerable de la textualidad oral en los textos escritos modernos” (2003b, 350). No obstante, Porcar Miralles (2012) ya había señalado el aumento del grado de planificación y la disminución del anclaje contextual, justamente a través del aumento en el uso de marcadores discursivos, en la anterior prosa científica del Renacimiento.

En una línea muy semejante, Octavio de Toledo acuñó ya en 2007 la etiqueta de "primer español moderno" para un período que sitúa desde 1675 hasta 1825, de manera que la tradicional lengua dieciochesca ve ampliarse sus límites hacia el XVII en sus comienzos y hacia el XIX en su final; en ese período sitúa el desarrollo de algunos fenómenos sintácticos en el plano oracional (2007 y 2008), y ha estudiado ciertos procesos de conexión discursiva en la incipiente lengua periodística (Borreguero Zuloaga/Octavio de Toledo y Huerta 2007). De esta forma, pues, con estos autores, a los que se podrían añadir otros, los que, p.ej., analizan también esa inicial prosa periodística (Ettinghausen 2000; Méndez García de Paredes 2008), o la médica entre el XVII y el XVIII (Gómez de Enterría/Martí Sánchez 2016), y otros algo más lejanos de la orientación que queremos dar a este trabajo, la historia del idioma en ese período, al que antes llamamos "oscuro y oscurecido", empieza a revelarse con cada vez mayor claridad. Pero, signo de los tiempos de la Filología actual, esta investigación se está realizando ante todo sobre textos que los historiadores de la literatura jamás incluirían en sus cánones: 
ello puede deberse a que no hay otros, o no hay otros muchos suficientemente atractivos, pero sobre todo a que la mirada del historiador de la lengua intenta, cada vez más, abrirse a más y más horizontes textuales ${ }^{3}$.

3 Para el trabajo que aquí se presenta, ha parecido de interés contar con textos de cada uno de los ámbitos en que con más fuerza se produjeron los intentos de innovación: la Medicina (con la Carta Philosophica Medica Chymica de Juan de Cabriada) ${ }^{4}$, las Matemáticas (con la Arithmetica demonstrada de Juan Bautista Corachán) ${ }^{5}$ y la crítica historiográfica (con De la corrupcion de las Chronicas impressas ${ }^{6}$ y las Memorias históricas del Rey D. Alonso el Sabio ${ }^{7}$, ambas de Gaspar Ibáñez de Segovia, marqués de Mondéjar). Como contraste se ha analizado también el texto de uno de los más notables representantes del reaccionarismo médico: los Avisos de la muerte... (o Tratado de la peste) de Juan de la Torre ${ }^{8}$.

La atención, como viene siendo habitual en los estudios de sintaxis histórica orientada discursivamente, se centrará en aquellos aspectos más relevantes para tal fin, en concreto los que tienen que ver con la construcción de las secuencias discursivas, analizables tanto en el plano oracional (perspectiva sintáctica, gramatical) como en el situado más allá de la oración (ilación discursiva, etc.). En último término, el objetivo consiste en averiguar si los intentos de renovación científica e ideológica se tradujeron igualmente en la renovación de los procedimientos expresivos; si, por el contrario, estos se atuvieron a las formas dominantes en la época, heredadas de épocas anteriores; y si los hechos lingüísticos detectados pueden inscribirse en la historia de unas determinadas formas textua-

3 No debería omitirse que dos de los historiadores que iniciaron este nuevo camino, Álvarez de Miranda y Girón Alconchel, fueron discípulos de Lapesa, el máximo representante, según algunos, de esa Historia de la lengua volcada casi en exclusiva hacia la lengua literaria.

4 Carta filosofica medico-chymica en que se demuestra que de los tiempos y experiencias se han aprendido los Mejores Remedios contra las Enfermedades... En Madrid: en la Oficina de Lucas Antonio de Bedmar y Baldivia..., 1687 (www.cervantesvirtual.com/buscador/?q=cabriada).

5 Arithmetica demonstrada theorico-practica para lo mathematico y mercantil. En Valencia: por Jayme de Bordazar, 1699 (http://bdh-rd.bne.es/viewer.vm?id=0000060328\&page=1).

6 De la corrupcion de las Chronicas impressas de nuestros Reyes... Manuscrito, s. a. (comienzos del s. XVIII). Se ha utilizado el ms. 1175 de la BNE, que, a falta de un más minucioso análisis filológico, parece ser el que menos errores contiene (hay otras copias: Mss. 5861, 10625 y 8949).

7 Memorias historicas del Rei D. Alonso el Sabio i observaciones a su chronica. En Madrid, en casa de D. Joachim Ibarra, 1777 [obra póstuma] (http://bdh-rd.bne.es/viewer.vm?id= 0000015582\&page $=1$ ).

8 Juan de la Torre y Valcárcel, Avisos de la muerte... (o: Tratado de la peste). En Madrid por Melchor Álvarez, 1681 (http://fondosdigitales.us.es/fondos/libros/2096/1/avisos-de-la-muertemanual-y-prompta-resolucion-para- preservarse-y-curarse-de-la- peste-por-el-doctor-d-iuande-la-torre-y-valcarcel/). 
les y en la constitución de determinadas tradiciones discursivas, o si obedecen a otros parámetros explicativos.

3.1 No obstante lo dicho, no deja de ser interesante señalar algunos hechos sintácticos, situados en planos "inferiores” de la construcción discursiva, pues con ellos: a) se comprueba, una vez más, la extraordinaria lentitud de los cambios sintácticos, en especial en lo referente a la desaparición de las formas perdedoras en la contienda; y b) se pueden caracterizar, precisamente por ese conservadurismo, en cierto modo las tradiciones textuales que se analizan.

Así, es notable comprobar cómo tanto Cabriada como de la Torre, innovador y reaccionario, coinciden en el amplio empleo del subjuntivo en -re (en alternancia con el presente de indicativo) para hipotetizar las distintas situaciones por las que puede pasar el enfermo, por las vicisitudes en la toma de medicamentos, etc., tanto en condicionales como en relativas, de generalización o no9 ${ }^{9}$ Cabriada, el innovador, mantiene con cierta firmeza una construcción tan anticuada como el infinitivo de sujeto no concertado: "aquello que ha mostrado ser cierto la Experiencia” (p. 20), “[...] que dize, inducirse la Calentura [...]” (p. 149). Por su parte, el matemático Corachán mantiene el clítico en posición posverbal tras pausa fuerte ("Divídese..."), y hace sistemático este orden en subjuntivos apelativos (prescripciones en la resolución de problemas: "Partase...”, “Digase...”) hasta el punto de convertirlo en característico de este tipo de tratados. Por su parte, Ibáñez de Segovia extrema el uso de las completivas (de OD o de sujeto) sin nexo, una disposición a veces elaborada, otras más inmediata, de reducida y vacilante vida en la historia del idioma: "dispuso se imprimiese [...]", "no se puede dudar la huviesse formado el Rei [...]”, y un largo etcétera, en Corrupcion; "notándole devia la mayor parte [...]”, "parece deve reducirse su nacimiento [...]”, "sabiendo passó con la Reina [...]”, etc., en Memorias; el abundante recurso a esta modalidad acaba constituyendo un rasgo de estilo (¿buscado?) de los textos del marqués de Mondéjar.

Finalmente, no se puede dejar de aludir a la presencia ocasional de hechos que, si bien presentes desde los orígenes del idioma, empezaban en esa época a ser desplazados de la escritura, para reducirse a la inmediatez comunicativa y acabar siendo considerados, incluso, como incorrecciones sintácticas. Así, la duplicación del relativo mediante un clítico (“[...] que por ser Materia tan curiosa, y necessaria, la tocaré [...]”, Cabriada, p.23s.); también se halla en Avisos (p.21). $\mathrm{O}$ la repetición del que introductor de completiva, normalmente por quedar la

9 Menos relevante es la conservación en Cabriada de -ra en la apódosis de condicional irreal, eso sí, temporalmente presente: “[...] que si escriviera oy, que nos enseñara mas grande Medicina” (p. 36). 
completiva en cuestión muy lejos del verbo regente de “decir” (así en Cabriada, p. 27, en Avisos, p. 27s.). Incluso puede hallarse el alejamiento del antecedente (un demostrativo aquel) respecto del relativo ("aquellas razones son iguales, cuyos antecedentes [...]”), construcción muy del gusto de Corachán, y solo presente en él. También son muy pocos los casos de un que introductor de justificaciones a posteriori o de difícil adscripción semántica ${ }^{10}$. La notable escasez de tales formas parece garantizar su práctica desaparición de la lengua elaborada escrita.

3.2 Evidentemente, no es solo la pertenencia de un texto a una determinada tradición lo que determina sus características de construcción sintáctica. Dentro de los textos, aun de los más diversos entre sí, pueden existir segmentos muy concretos que se insertan en tradiciones discursivas específicas y es esto lo que determina su forma. Entre esos segmentos bien delimitados están los prólogos, que suelen tener una sintaxis propia, diferente de la del resto del texto y semejante de unos a otros. Esto se muestra de manera muy marcada en Cabriada, tanto en la dedicatoria al conde de Monte-rey como en la dirigida al enigmático Filiatro. En ellas la elaboración sintáctica es extrema, pero ello no se realiza mediante la complejidad en las relaciones interoracionales y en la incrustación de unas secuencias en otras: por el contrario, no hay gran variedad en la hipotaxis ni se echa mano de los tipos más complejos, ni la mayoría de los párrafos contiene, salvo situaciones muy concretas, secuencias superiores a las bi- o tri-oracionales ${ }^{11}$. La elaboración se consigue mediante el orden casi sistemático adjetivo - nombre, la constante inserción de gerundios explicativos, incisos y paréntesis, acumulación de sintagmas nominales (sustantivos que se prolongan en relativas explicativas), contraposiciones y paralelismos... También ayudan disposiciones de orden de los elementos, más o menos marcadas: anteposición de subordinadas introducidas por como (orden habitual en casi todos sus valores), de OD focalizados ("Sombras [...] pretendo desvanecer [...]”, fol. 15), de predicado nominal en frases atributivas. De la época, herencia de la escritura barroca conceptista, procede el gusto por elipsis, zeugmas, o infinitivos independientes tras exclamación: "Honroso ardor! Querer [...]” (fol.6) ${ }^{12}$.

10 Solo en Avisos se hallan con relativa frecuencia estos que, incluso encadenados entre sí: “[...] no será malo, que solo hago mencion de lo indiuidual, que basta” (p.15).

11 En la primera dedicatoria, de 14 párrafos detectados, 6 son monooracionales, 3 de dos oraciones y 4 de tres, y solo un párrafo llega a las nueve oraciones. En la segunda, de 21 párrafos, 7 son monooracionales, otros 7 constan de dos oraciones, 2 con tres, una con cuatro, y un caso, respectivamente, de secuencias de 7, 9, 6 y 10 oraciones.

12 Es notable que en un párrafo complejo, que acumula infinitivos y gerundios, el autor defienda huir de la afectación, con ecos de Valdés, más que por motivos estéticos por considerarla encu- 
Algo así se encuentra en el prólogo de los Avisos de Juan de la Torre, con procedimientos muy parecidos, pero de nuevo con poca hipotaxis y esta dispuesta en secuencia lineal. Sin embargo, estas especificidades no son tan marcadas en otros prólogos. En Corachán, la inicial dedicatoria a San José solo muestra algún caso de anteposición de adjetivo o de predicado nominal, y completivas duplicadas; el prólogo propiamente dicho presenta sintaxis simple y lineal (dominan ampliamente los párrafos monooracionales y los de dos y tres oraciones, si bien hay presencia de secuencias más amplias, alguna hasta de 19 oraciones), sin órdenes marcados de elementos, y solo con algunas estructuras duales; en algún caso, no obstante, la estructuración se complica hasta el punto de perderse el hilo del discurso (en el párrafo iniciado por "Pero advierto, que [...]" ese verbo queda sin completiva objeto). Y en "Al lector”, prólogo de las Memorias de Ibáñez de Segovia, la sintaxis de relaciones interoracionales es simple en general en su disposición (salvo parágrafos como el 3 o el 8), pero con proliferación de sintagmas nominales, gerundios, participios concertados..., y con claro dominio de los párrafos amplios, de más de cinco oraciones componentes (es notable que en este autor sea el texto central el de configuración mucho más compleja y alambicada que el prólogo).

3.3 Ya se ha señalado cómo la amplitud y complejidad de los párrafos puede conseguirse por otros procedimientos que por el mayor o menor número de secuencias oracionales con núcleo verbal en forma personal que los integran. Sin embargo, este parámetro sigue siendo decisivo a la hora de calibrar dicha complejidad, caracterizar los distintos modos de construcción sintáctica y establecer los condicionantes decisivos.

Pues bien, justamente en este punto son notables, y relevantes, las diferencias observables en los textos analizados. Hay un claro contraste entre Corachán, en el que la inmensa mayoría de párrafos detectados no incluye más de cinco núcleos oracionales (90 de 111: $81 \%$ ), con amplia presencia de períodos monooracionales (15) y de dos (23) y tres oraciones (27), lo cual es uno más de los rasgos de su simplicidad construccional; e Ibáñez de Segovia, que en Corrupción ofrece mayoría de períodos con más de cinco núcleos oracionales (16 frente a 12), y en Memorias lleva al extremo la ramificación oracional de los períodos: 24 con más de 5 núcleos oracionales frente a solo 5 por debajo de esa cifra. Entre ellos el texto de Juan de la Torre se sitúa en un término medio (35 párrafos por debajo de

bridora de la falsedad: “[...] proponerla con llaneza desnuda, huyendo la afectacion, con que la sagazidad (que se precia de ingeniosa) suele introduzir lo falso por verdadero, y ocupar los Animos con aparentes sofisterias, y equivocos Argumentos” (p.3). 
5 oraciones, 30 por encima, si bien con ocasionales períodos amplísimos, de hasta 18 núcleos oracionales); particularidad de este autor es la frecuencia con que sus períodos monooracionales no incluyen ningún verbo regente, solo una aparente subordinada ("El segundo, si ay [...]", p. 4), o nada ("Otra, y mas suaue [...], "Segunda gerarquia [...]”, a lo que siguen citas literales de autores, p.12), muestras de un intenso gusto por las elipsis, rasgo de época, pero que también proporciona una notable rapidez expositiva al texto (contrapesada por las abundantes acumulaciones de sustantivos con que se encadenan remedios, medicinas, etc.).

Pero el caso quizá más llamativo es el del médico Cabriada. En las páginas que dedica a narrar la enfermedad del conde de Monte-rey a modo de relación de hechos, todos los períodos, salvo uno (es decir, 68) constan de menos de cinco núcleos oracionales, siendo mayoría relativa (24 casos) los períodos monooracionales. Sin embargo, cuando pasa a exponer las causas de las enfermedades, la situación se equilibra, si bien solo relativamente: solo 4 períodos monooracionales, y un total de 58 con menos de cinco núcleos oracionales, frente a 29 que superan esa cifra; en suma, si bien siguen siendo mayoría los períodos relativamente "cortos", su dominio ya no es tan aplastante. Es evidente que las diferencias en este punto van más allá de la época o del tipo de texto y tienen que ver, básicamente, con los propósitos enunciativos que en cada caso se plantea el texto. Como se verá a continuación, tanto en Cabriada como en el resto de autores, las diferencias vinculadas a este parámetro van de la mano con otras.

3.4 Desde el inicio de la subida del romance castellano a la escritura, los textos en prosa han manifestado de forma constante un notable apego por las construcciones con subordinación oracional, de todo tipo, frente a los textos poéticos, en los que la parataxis asindética, la tradicional yuxtaposición, está mucho mejor representada. No obstante, este cuadro, que encaja bien con lo que se puede detectar en los primeros siglos de escritura castellana, no refleja las vicisitudes posteriores, con ascensos y descensos alternativos, y a veces compensados, entre unos modos de organización $u$ otros y variaciones en su adscripción a distintos tipos textuales. En este sentido, la imagen que se dibuja, más que de un proceso evolutivo constante en una dirección (tópicamente, de la parataxis a la hipotaxis), es la de un movimiento en zigzag en el que las distintas situaciones, tanto para la prosa como para el verso, dependen de las clases de texto y las situaciones enunciativas, sin dibujar ningún tipo de dirección en los cambios; por el contrario, parece más bien que nos hallamos ante procesos cíclicos, recurrentes, que, al menos en los textos considerados literarios, pueden venir condicionados por guías de comportamiento codificadas (la Retórica, latina, medieval o renacentista).

En el siglo XVII, continuando un movimiento iniciado a finales de la centuria anterior, la prosa, en especial la didáctica o doctrinal (Quevedo, Gracián...), 
había abrazado la unión por mera yuxtaposición de secuencias breves (cfr., entre otros, Girón Alconchel 2003b, 335s.), un movimiento que opone claramente tales moldes retóricos a los más circulares y complejos ("ciceronianos") de épocas anteriores. Sin embargo, ello no parece haberse extendido mucho más allá de ese tipo de textos. En los aquí analizados, la hipotaxis es, como era tradicional, la relación interoracional dominante, en proporciones muy elevadas ${ }^{13}$. Sin embargo, un recuento de este tipo no da sino una imagen en bruto, que ha de precisarse discriminando los datos que el análisis ofrece. En primer lugar, ha de recordarse que la unión paratáctica en ciertos momentos se intensifica, no en Cabriada o Ibáñez de Segovia, que entre las oraciones del período apenas la usan, sino en los Avisos de de la Torre, al yuxtaponer las partes de una exposición (p.ej. p. 7), o en Corachán, donde la yuxtaposición se acerca al $10 \%$ del total de relaciones interoracionales, y aparecen muy especialmente en los párrafos de descripción y enseñanza de operaciones aritméticas (p.ej. p. 13). Por otro lado, ha de señalarse que, como es también muy habitual, los tipos de subordinación aparecen en proporciones muy disímiles: en todos los textos, las relativas de cualquier tipo (explicativas o especificativas, sin antecedente constitutivas de actante oracional) son, con mucho, las más empleadas ${ }^{14}$, seguidas, a mayor o menor distancia, por las completivas; son tipos tenidos tradicionalmente por más simples, si bien las segundas y parte de las primeras (relativas especificativas y sin antecedente constitutivas de actante) suelen incluirse entre las subordinadas propias, de mayor integración sintáctica, mientras que las otras (relativas explicativas) constituyen un tipo de hipotaxis más "suelta", de menor integración.

Para el resto de tipos, de presencia siempre minoritaria, han de destacarse no obstante situaciones merecedoras de explicación particular. Así, en los fragmentos de Cabriada donde este explica las causas de las enfermedades, pero sobre todo en Avisos, donde el autor prescribe los remedios en los distintos casos que puedan producirse, el uso de condicionales (en -re o en presente de indicativo) se incrementa para delimitar tales situaciones hipotéticas. Del mismo modo, en uno y en otro textos se observa también un aumento en el uso de causales, dirigidas a la explicación de los procesos o a la justificación de las prescripciones realizadas. En Corachán se hallan temporales con valor definidor de conceptos

13 En Cabriada, según las partes del texto, entre un 83 y un $90 \%$ del total de conexiones; en Avisos, otro 83 \%; en Corachán disminuye ligeramente hasta un 72,4 \%; y en Ibáñez de Segovia sube al 88,6 \% en Corrupcion, y hasta el 91,9 \% en Memorias, texto de elevadísima elaboración. 14 En Cabriada, 63,3 \% del total de subordinadas en el relato de la enfermedad del conde, pero solo un $32 \%$ al discutir las causas de las enfermedades (aun así, la minoría mayoritaria). 48,6 \% en Avisos. 38,5 \% en Corachán (también, de lejos, el grupo mayor de subordinadas). Y 54 \% y $49 \%$, respectivamente, en las dos obras analizadas de Ibáñez de Segovia. 
("la primera quando espressa [...] La segunda quando no se determina [...]", p. 4), y abundantes condicionales para el planteamiento de los problemas (hipótesis expresables también con otros procedimientos); en el planteamiento de problemas complicados la complejidad de los párrafos se incrementa mediante el aumento de la subordinación (p.ej. p. 222s.). Igualmente, la cadena de exposición de hechos y explicaciones que ofrece Ibáñez de Segovia en sus dos textos explica la relativa mayor presencia de causales. Pero es notable en Memorias la elevada presencia de modales con como y según destinadas sobre todo a introducir las citas de autoridad, con que el autor pretende afirmar lo dicho por él (uso este de larga tradición en la ensayística anterior, pero también en la posterior).

Por otro lado, la disposición de las secuencias oracionales con subordinadas es, normalmente, lineal, de modo que se mantiene el orden regente - regida(s), con el regente habitualmente en la parte inicial del período, y ello incluso en enunciados complejos, con digresiones y paréntesis varios, tal como se ve en Cabriada (p. 15s.). En este autor, solo en determinadas situaciones, cuando la complejidad formal del párrafo acompaña a especulaciones que se pretende marcar, se da la inversión del orden, más allá de condicionales o causales de causa consabida: "Y porque pareció [...]" (p. 16), o la muy frecuente de completivas (de OD y de sujeto): "Que hizieran Hombres Grandes [...] tuve por mas NOVEDAD” (p. 17), en ambos casos dentro de una ponderación polémica de las valiosas aportaciones de los jóvenes, frente a la cerrazón de los médicos de mayor edad. Puede ocurrir, incluso, que un párrafo contenga toda una serie de subordinadas previas (iniciadas por un gerundio: "Considerando [...]") y para encontrar el núcleo principal haya que ir al párrafo siguiente, separado por punto y aparte ("Hize [...]") (p. 14). Este incremento de la subordinación en los períodos se acompaña en esos casos de otros procedimientos que elevan la complejidad discursiva: así en las quejas ante la penosa situación de la Medicina en España, la sintaxis no solo se ramifica en subordinadas sino también con gerundios coordinados entre sí a distancia y con relativas que se incrustan entre sí (p. 26). En alguna ocasión, la complejidad se acompaña de un juego de contraposición de términos contrarios y de paradojas que recuerda las técnicas conceptistas (así, en p. 37, donde enfrenta el aborrecimiento que produce la ignorancia de la Química en Medicina con el amor que genera su conocimiento). En los Avisos de de la Torre, por el contrario, la complejidad no surge tanto de la disposición y tipos de subordinación utilizados cuanto de la acumulación nominal (en secuencias yuxtapuestas o coordinadas), o de infinitivos ${ }^{15}$; el gusto por las elipsis (muy habituales las de verbos regentes, que en

15 En bastantes ocasiones, estos infinitivos, que tendrían que depender de un deber implicado por el discurso (en las prescripciones de remedios), acaban adoptando un valor claramente im- 
ocasiones han de inferirse a partir del mismo discurso) hace oscuros algunos de esos párrafos. Los períodos extensos formados por la acumulación de oraciones se consiguen mediante la acumulación lineal de, sobre todo, relativas y causales a un núcleo regente inicial (así, en p. 5: "Es verdad, que [...]”). Solo en algún caso se produce un orden más envolvente, a partir de la esperable anteposición de una prótasis condicional, a la que se van encadenando, en incrustaciones de dos y hasta tres niveles, relativas y temporales explicativas ("Pero si salen parotidas criticas, que es quando vence la enfermedad [...]”, p. 20), todo lo cual se recoge en un encapsulador ("en qualquiera destas dos condiciones [...]"), que da paso al núcleo principal del período. En Corachán la linealidad en la disposición de las secuencias oracionales (regente más regida(s)), además de la poca variedad en las relaciones utilizadas, es aun más llamativa: así, se posponen las causales, como justificaciones a lo previamente dicho, y se acumulan linealmente las adversativas, que matizan o introducen casuísticas particulares en los problemas que se plantean, condicionales para las posibles situaciones, consecutivas (con de suerte que y con que) para la solución de los problemas y el orden lógico del razonamiento, etc. ${ }^{16}$ Es notable en Corachán el uso de como para introducir ejemplos, casos, de lo dicho previamente, pero sin que pueda considerarse propiamente como nexo conjuntivo, pues tras él pueden aparecer secuencias de todo tipo (“como por la vnidad dezimos vn Angel” (p. 2), “[...] zeros, que solo sirven de llenar lugar: Como para escribir con guarismos trescientos veinte y seis, escrivase vn 3” (p.12), etc.). Por el contrario, Ibáñez de Segovia es el único que sigue prefiriendo el orden envolvente para sus períodos, extremadamente largos y complejos por lo general, con anteposición de concesivas, gerundios, etc. al núcleo principal; y ello tanto en Corrupcion como en Memorias ${ }^{17}$. Pero también en aquellos períodos, bastantes, que adoptan un orden más lineal, con el núcleo principal

perativo. $\mathrm{O}$ en apódosis de condicionales: "Si se hiziere sangria, tener preuenidas [...]" (p.19), con lo que el infinitivo, cargado de valor apelativo, parece ocupar el núcleo de la apódosis (en otras ocasiones, falta todo verbo: “[...] que si pide precisa euacuacion [...], muy poco, y repetidas vezes" (ibid.).

16 Solo en alguna ocasión se produce una anteposición focalizadora de subordinada, en este caso con interrogativa indirecta: "Qval sea [...] ya queda explicado” (p. 226). Eso sí, en los razonamientos matemáticos (véase, p.ej., el Comentario de p. 234) suele anteponerse una condicional hipotética (pero en presente de indicativo), y ya a la apódosis subsiguiente se le van encadenando subordinadas, completivas y relativas fundamentalmente.

17 En Memorias, además, la frase se complica por la abundante presencia de los nombres propios de los personajes implicados, acompañados de aposiciones explicativas que refieren sus rangos, peculiaridades, etc. El tradicional gusto por los sintagmas binarios ("no progresivos"), escaso en los otros autores, en él se dispara, aumentando así también la cargazón de la frase. Del mismo modo, el uso de correlaciones es también muy superior al de los otros textos analizados. 
al comienzo del conjunto, se ramifican abundantemente en subordinadas (sobre todo relativas) y otros tipos de dependencia sintáctica. Además, la recurrencia o incrustación de unas subordinadas en otras, que en los otros textos se daba casi solo con relativas, en Ibáñez de Segovia se produce con todo tipo de subordinadas (causales que encierran concesivas, etc.). Hasta tal punto ello es así que en ocasiones resultan confusas las vinculaciones exactas de dependencia o las referencias anafóricas de los relativos.

3.5 La vinculación de los párrafos o de los parágrafos ${ }^{18}$ entre sí es uno de los parámetros más relevantes para establecer el tipo de construcción discursiva y textual que se produce en cada caso, así como para establecer pautas evolutivas al respecto. Que haya o no vinculación, y cómo se establece esta, sí es uno de los aspectos en que pueden señalarse ciertas pautas evolutivas.

En los textos aquí analizados, las proporciones de vinculación o no dependen fuertemente de cada texto y de los contenidos diversos en cada uno de ellos. Así, en Cabriada la parte en que se relata la enfermedad del conde apenas si muestra conexión entre parágrafos, siendo la yuxtaposición el modo de secuencia claramente preferido (15 frente a dos casos), lo que contribuye, junto con otros rasgos vistos en epígrafes anteriores, a la extrema vivacidad en el relato. También aquí la yuxtaposición entre los párrafos que integran esos parágrafos es abundante (11 casos), si bien el empleo de remisiones anafóricas explícitas (11 casos también), junto a un único caso de y extra- o supra-oracional, hace que aquí la yuxtaposición no resulte tan llamativa. En las secuencias donde se explican las causas de las enfermedades se produce igualmente un equilibrio, tanto en parágrafos como en párrafos, entre secuencias yuxtapuestas y vinculadas por algún marcador explícito. En Avisos la mera yuxtaposición también es abundante, pero nunca supera al conjunto de procedimientos explícitos de conexión. Idéntica situación se produce en Corachán entre párrafos, si bien en la vinculación entre parágrafos es superior la yuxtaposición (aunque en ocasiones haya reiteración de la parataxis con $y$, p.ej. para sumar argumentos (p. 6s.). Y, por último, en Ibáñez de Segovia la simple yuxtaposición en la conexión es minoritaria frente a los diversos procedimientos ilativos. En suma, en estos textos no se comprueba el aumento de la cohesión marcada explícitamente que Girón Alconchel había señalado para otros textos coetáneos (2003b, 348-350). En este sentido, tampoco se observa avance, sino todo lo contrario, respecto de lo visto en textos pre-periodísticos del XVII,

18 En estos textos, todos impresos salvo el manuscrito de Corrupcion, la disposición en parágrafos viene ya dada por el mismo texto. La puntuación, si bien diferente de la actual, sí ayuda a segmentar los párrafos o períodos en cuyo interior se producen las relaciones interoracionales. 
también notablemente reacios a la conexión supraoracional; y hay un claro retroceso frente a algunos textos de “arbitristas” donde la conexión explícita, con variaciones, empezaba a ser dominante; ahora bien, esa independencia de parágrafos y párrafos parece, sí, ir en consonancia con lo que se estaba produciendo en la lengua literaria de la época, pero aun no con el desarrollo posterior de la lengua informativa y ensayística (cfr. Cano 2016).

Sin embargo, los procedimientos de conexión explícita entre períodos y parágrafos son extraordinariamente pobres, y en ningún caso suponen avance frente a textos anteriores (en realidad, constituyen un claro retroceso al respecto), y, por tanto, no parecen prefigurar el tipo de prosa ensayística posterior, al menos en este parámetro. En efecto, con algunas excepciones, y obviando las conexiones a través de las redes léxicas ${ }^{19}$, el mecanismo más utilizado son las remisiones anafóricas mediante pronombres (demostrativos, identificativos como mismo, la originaria expresión locativa de aquí (en Cabriada), etc.). Siguen los nexos, conjunciones, coordinantes, funcionando ahora en una dimensión superior: en primer lugar, la copulativa $y$, acompañada en ocasiones de refuerzos ( $y$ assi en Cabriada, Avisos e Ibáñez de Segovia), seguida del contrapositivo pero. Se utilizan también adverbios con sentido de adición: tambien, asimismo, assi; y en Corachán adverbios temporales: luego, despues. $\mathrm{O}$, solo en Corachán, nexos subordinantes ante los que la pausa reflejada en la puntuación ha disuelto la estricta relación sintáctica: porque, de suerte que y con que, a los que habría que añadir un uso de por donde en Ibáñez de Segovia, y de donde en Cabriada. Finalmente, apenas hacen acto de presencia elementos que se habían configurado, o se estaban configurando, como conectores especializados en este tipo de vinculación: los conectores de contraposición no obstante en Cabriada, si bien aún unido en un caso al demostrativo esto, por lo que ahí sigue constituyendo una construcción absoluta; y sin embargo en Ibáñez de Segovia, alguna vez tras pero; los ilativo-consecutivos por consiguiente (Cabriada) y pues, algo más frecuente, de colocación y valores diversos; a ellos habría que sumar algún recapitulador (en suma, en Cabriada), ordenadores: en fin (Cabriada, Avisos), finalmente (Corachán), además de las ordenaciones establecidas mediante numerales ordinales (primero, segundo, etc., muy usadas por todos estos autores); y por vltimo (en Cabriada), o las distribuciones "por una parte... por otra parte" (p.ej. en Cabriada).

Las necesidades argumentativas provocan una cierta acumulación de estos conectores. Así, en Cabriada (p. 22) el parágrafo iniciado por "Tambien es nuevo invento [...]” añade a esa conexión inicial, dentro del párrafo, otras establecidas a través de por consiguiente y de donde, el cual a su vez refuerza su valor con la

19 O de repeticiones y paralelismos: así la secuencia de "Hallé [...] Hallé [...]” en Cabriada (p. 12). 
expresión que le sigue ("de donde se sigue por legitima consequencia [...]"). O el refuerzo en la escala argumentativa logrado mediante el reiterado Más con que inicia los párrafos que desgranan los elementos de la argumentación ("Mas: Experimentamos, que los Perros [...]", ibid.). Para rematar la argumentación, aparte de algunos usos peculiares como los señalados para Corachán (con que, de suerte que), el más habitual es pues, intercalado normalmente detrás del primer elemento de la oración, si bien en algún momento, en Corachán aparece en posición inicial, introduciendo una reacción a lo que se acaba de decir, en una forma que recuerda el pues de réplica tan propio de la oralidad ("el tercer guarismo del senario es 5. pues digo quinientos" (p.11), "Pues como se nombrarà?” (p. 14), "Pues para que no causen confusión [...]”, ibid., etc.).

3.6 La presencia del enunciador en su enunciado a través de manifestaciones lingüísticas es, en la escritura, tan antigua como esta. Sin embargo, no todos los tipos de texto la muestran en iguales proporciones o con las mismas formas. Los textos aquí analizados manifiestan continuidades y relevantes novedades respecto de la inscripción del autor en su texto dentro de la tradición expositiva y científica a la que se adhieren.

Continúan una antigua tradición (en castellano pueden hallarse desde, al menos, los textos alfonsíes) las expresiones en que el autor detalla cómo ha organizado el texto, o cómo va a pasar de una parte a otra, o de un tema a otro. En Cabriada ello se hace en primera persona: "Passo al SEGVNDO FUNDAMENTO [...]” (p. 26), “[...] dexando esto para mejor ocasion, vengamos al TERCER GENERO [...]” (p. 34), etc.; o iniciando una nueva vía discursiva con un Aora que da paso a nuevos contenidos. Más ocasional es el uso de la primera persona, plural, para recuperar un tema, en Avisos ("Hemos dicho [...]", p.11; "Bolvamos ya à [...]”, p. 18). Menos frecuentes, en cambio, son tales consideraciones metatextuales en los otros autores, si bien Corachán recurre igualmente a la primera persona para justificar la ordenación elegida por él para su texto (“[...] que omito por no ser molesto”, p.11), justificación más desarrollada en otros momentos ("Bien conozco, que [...] Pero no he podido omitirlas [...] diré lo mismo [...]", p. 14); y en algún caso, no solo hay consideración metatextual sino también metalingüística al proponerse un modo discursivo afecto a un modelo común de hablar ("Pero vamos al caso, que hemos de hablar como todos hablan", p. 318). Estas consideraciones metalingüísticas (explicitación de los modos en que se va a construir el discurso) son también frecuentes en Cabriada: "(Tocarê esto brevemente, por no dilatarme)" (p. 22), "Mas claro y mas breve: [...]" (p. 35). En Avisos solo alguna vez el autor justifica su decir ("[...] no será malo, que solo hago mencion de lo indiuidual, que basta”, p.15). Y en Ibáñez de Segovia es también 
ocasional usar la primera persona, solo para una autocita ("El segundo Exemplar de los quatro que dixe [...]”, Corrupcion, p. 8).

En Cabriada particularmente se halla con abundancia una muestra de subjetividad solo presente alguna que otra vez en Corachán: la calificación del enunciado que sigue mediante un verbo ilocutivo en primera persona ("Pregunto: Si [...]", p. 15, "Pregunto [...]", p. 38), dentro de un contexto polémico cargado de justificaciones y argumentaciones. En algún caso ello se produce en un contexto imaginado de preguntas y respuestas, con las que Cabriada intenta reforzar sus argumentos, debilitando los de su supuesto contrario ("Pregunto [...] Veo que me responderán [...] Pero yo te demonstraré [...] Y por consiguiente digo [...]”, p. 33s.). El “yo" vuelve a aparecer en el matemático Corachán, en bastantes casos con funciones distintas: alguna vez, sí, como manifestación subjetiva de especulación tras consideraciones previas ("Dixera yo [...]”, p. 3) ${ }^{20}$; o en un contexto ficticio de pregunta - respuesta en la exposición ("Pues como se nombrarà? Digo que Partes [...]”, p.14); pero más frecuentemente con valor de generalización inclusiva en explicaciones y descripciones, sobre todo en plural, como es aún hoy habitual en los textos científicos y expositivos ("Si atendemos [...] hallarémos [...]", p. 8); o como sujeto ficticio en la exposición de problemas y en las hipótesis que estos contienen ("Supongo, pues, que se ha de nombrar el mismo numero [...]", p. 10), a la que modernamente se prefiere la tercera, forma mucho más "objetiva”; o como sujeto ficticio igualmente de los pequeños relatos con que Corachán plantea hipotéticos problemas matemáticos para su resolución (en varios casos el sujeto protagonista de esos relatos es un “yo”, en otros, personajes diversos nombrados por sus oficios o de manera indefinida: “Vno, preguntando [...]”, p. 319).

Para reforzar la propia argumentación y disminuir el valor de la (posible) contraria hasta llevarla al absurdo, se echa mano de la interrogación retórica, en la que el contenido del enunciado interrogativo es, según los casos, lo que el autor defiende y no puede ser de otra manera, o lo defendido por su adversario y es imposible que sea. Este recurso es muy empleado por Cabriada, en una clara muestra más de la dimensión subjetiva de su argumentación, de su implicación en la defensa de sus propias ideas y convicciones en abierta polémica y enfrentamiento con las posturas tradicionales. Las interrogaciones pueden encadenarse entre sí, en dependencia las posteriores respecto de las primeras, sin marca explícita de ello, solo reconocible por la elipsis ("[...] quien no sabe, que lo que no alcançaron los ANTIGVOS, se revelô à los MODERNOS? Lo que se le passò â la Grandeza del SABIO, hallô el PARVVLO? [...]”, p. 17); y pueden incluir, o partir de, alguna expresión indicadora de verdad asentada ("Pues què será, quando las cosas son de su

20 Obsérvese la persistencia del valor de "subsecuencia" en dixera, hoy diría. 
naturaleza vtiles, y laudables? No merece vna cosa aborrecimiento [...]”, p. 37). En Avisos la presencia de la interrogación retórica es excepcional, aunque cuando lo hace, es igualmente para reforzar el previo decir (una prescripción médica). En Corachán, como ya se ha señalado, las interrogaciones forman parte del juego expositivo, no están destinadas a reforzar la enunciación del locutor. Y en Ibáñez de Segovia apenas si se usa alguna vez con el mismo objetivo, reforzar los argumentos en pro de la autoría de Alfonso el Sabio de su Estoria ("Por que cómo se podrá inferir [...]?”, p.7s.).

La manifestación lingüística del enunciador tiene otros procedimientos, menos constantes: la exclamación, con valor de lamento u otros, en Cabriada (“O Buen Dios!”, p.30), a veces seguida por interrogaciones retóricas (así, en p. 37), e incluso por un diminutivo minusvalorador y despectivo ("Què buena Doctrina es esta, para los que à qualquier cosita [...]”, p.156). No es Avisos, según se ha señalado, un texto proclive a la subjetividad, y, salvo lo indicado más arriba, no hay otras muestras de ella (a no ser la fraseología coloquial que simboliza lo que está diciendo: "y no es vezino para tan dentro de casa”, p. 19). Ni Corachán, que solo se permite una frase nominal valorativa, cuyo sentido solo se hace patente por el cambio de isotopía discursiva y la interpretación resultante ("Tiempo mal gastado en cosa de tan poca importancia”, p.18). Nada de esto se halla tampoco en Ibáñez de Segovia, salvo alguna expresión de evidencialidad ("Este Libro que se cita, es, sin duda [...]", Corrupcion, p.4).

4 El recorrido por estos textos ha mostrado semejanzas y diferencias mutuas, a la vez que semejanzas y diferencias con textos anteriores de la misma tradición textual y también con los que continuarían y enriquecerían dicha tradición. En principio, todos ellos parecen compartir una cierta linealidad en la disposición de las secuencias interoracionales: los párrafos envolventes, tan del gusto de la prosa expositiva medieval o incluso renacentista, no hacen acto de presencia sino en momentos determinados, de mayor exaltación argumentativa (Cabriada) o retoricista (Ibáñez de Segovia). En este sentido sí engarzan con la prosa doctrinal barroca, conceptista, y prefiguran el posterior lenguaje del ensayo. Comparten igualmente el poco peso de las relaciones supraoracionales explícitas y la escasísima presencia de conectores especializados en esta función: ello no supone ningún avance respecto de la prosa informativa o de política económica de comienzos del XVII, sí encaja más con la lengua literaria de ese período, pero se aleja así del ensayo posterior, donde tales relaciones se configuran explícitamente (es notable, además, la práctica ausencia de “encapsuladores” en estos textos).

Hay diferencias debidas a la naturaleza del contenido de los textos: así, contrastan de forma abrupta las exposiciones y los planteamientos matemáticos de Corachán, en general de notable sencillez expositiva, con la prosa compleja, ra- 
mificada, extensa, de Ibáñez de Segovia: parece como si el lenguaje humanista, historiográfico, se resistiera a desprenderse de los antiguos oropeles expresivos. $\mathrm{Y}$ en los textos de Medicina contrasta también violentamente el fuerte subjetivismo polémico de Cabriada, manifestado lingüísticamente de diversas maneras, algo propio de quien se propone enfrentarse con la tradición anquilosada para proponer y defender los nuevos métodos, con la constante objetividad expositiva de los Avisos, que parece desprenderse de quien considera estar suministrando certezas inamovibles, que se justifican por sí mismas, y que no son objeto de discusión posible; en este texto, la complejidad viene de la extrema acumulación de nombres que designan los muy variados remedios que se prescriben.

En suma, la tradición textual a que pertenecen estos textos explica algunos de sus más notables rasgos lingüísticos. Pero no todos: aquello de lo que hablan, los distintos objetivos y actuaciones enunciativos, y, en último término, la irreductible individualidad de los autores son también parámetros que el análisis histórico-lingüístico de las tradiciones textuales y discursivas no puede relegar al olvido en ningún momento.

\section{Bibliografía}

Álvarez de Miranda, Pedro (1992): Palabras e ideas: el léxico de la llustración temprana en España (1680-1760), Madrid, Real Academia Española.

Álvarez de Miranda, Pedro (1993): “Las academias de los novatores”, en: Evangelina Rodríguez Cuadros (ed.), De las academias a la Enciclopedia: el discurso del saber en la modernidad, Valencia, Alfons el Magnànim, 263-300.

Álvarez de Miranda, Pedro (1996): “La época de los novatores, desde la historia de la lengua”, en: Studia Historica. Historia moderna 14, 85-94.

Álvarez de Miranda, Pedro (2008): “Una autobiografía del 'tiempo de los novatores': las Memorias de Raimundo de Lantery”, en: Criticón 103/104, 9-20.

Borreguero Zuloaga, Margarita/Octavio de Toledo y Huerta, Álvaro S. (2007): "Presencia y función de los encapsuladores en las crónicas periodísticas del s. XVII”, en: Philologia Hispalensis 21, 119-153.

Botella Ordinas, Eva (2005): “Los novatores y el origen de España. El vocabulario hispano de probabilidad y la renovación del método histórico en tiempos de Carlos II”, en: Obradoiro de Historia Moderna 14, 39-64.

Bustos Tovar, José Jesús de (1981): “Aportaciones léxicas y otras cuestiones idiomáticas en los textos de la época de Fernando Vl”, en: La época de Fernando VI. Ponencias leídas en el coloquio conmemorativo de los 25 años de la fundación de la Cátedra Feijoo, Oviedo, Universidad de Oviedo, Cátedra Feijoo, 337-352.

Cano Aguilar, Rafael (1983): “Sobre la sintaxis de Quevedo en 'La hora de todos'”, en: Serta Philologica F. Lázaro Carreter, t. 1, Madrid, Cátedra, 99-107.

Cano Aguilar, Rafael (2005): “¿'Lengua’ o ‘lengua literaria’?: reflexiones en torno a los estudios lingüísticos sobre el español de los Siglos de Oro”, en: Iberoromania 62, 44-58. 
Cano Aguilar, Rafael (2006): "El español del siglo XVII a la luz de las Gramáticas de Correas", en: José J. Gómez Asencio (ed.), El castellano y su codificación gramatical. Vol. II. De 1614 (B. Jiménez Patón) a 1697 (F. Sobrino), Burgos, Instituto Castellano y Leonés de la Lengua, 549-569.

Cano Aguilar, Rafael (2016): “Nuevos textos, nuevos discursos en la época de Cervantes”, en: Marta Fernández Alcaide/Elena Leal Abad/Álvaro S. Octavio de Toledo y Huerta (eds.), 85-106.

Ettinghausen, Henry (2000): "Tension and affirmation in the Seventeenth-Century Spanish Press”, en: Forum for Modern Language Studies 36/3, 254-265.

Fernández Alcaide, Marta/Leal Abad, Elena/Octavio de Toledo y Huerta, Álvaro S. (eds.) (2016): En la estela del Quijote. Cambio lingüístico, normas y tradiciones discursivas en el siglo XVII, Francfort del Meno etc., Lang.

Fernández Rodríguez-Escalona, Guillermo/del Brío Carretero, Clara (2006): “La concepción barroca del hablar: la dificultad”, en: José Jesús Bustos Tovar/José Luis Girón Alconchel (eds.), Actas del VI Congreso Internacional de Historia de la Lengua Española, t. 2, Madrid, Arco Libros, 1865-1881.

Garatea Grau, Carlos (2005): El problema del cambio lingüístico en Ramón Menéndez Pidal, Tübingen, Narr.

Girón Alconchel, José Luis (2003a): “Gramática y discurso en la época de Calderón”, en: Analecta Malacitana, Anejo XLVII. El mundo como teatro. Estudios sobre Calderón de la Barca (ed. de José Lara Garrido), 151-174.

Girón Alconchel, José Luis (2003b): “Evolución de la cohesión en el discurso ensayístico entre 1648 y 1726”, en: id./Francisco Javier Herrero Ruiz de Loizaga/Silvia Iglesias Recuero/Antonio Narbona (eds.), Estudios ofrecidos al profesor José Jesús de Bustos Tovar, t. 1, Madrid, Complutense, 331-360.

Girón Alconchel, José Luis (2004): “El hombre práctico (1686) de Gutiérrez de los Ríos: el español de finales del XVII”, en: Isaías Lerner/Roberto Nival/Alejandro Alonso (eds.), Actas del XIV Congreso de la Asociación Internacional de Hispanistas, t. 1, Newark (Delaware), Juan de la Cuesta - Hispanic Monographs, 251-264.

Girón Alconchel, José Luis (2012): “El cambio y el no cambio gramatical en el relato histórico en la transición del siglo XVII al XVIII”, en: Cuadernos Dieciochistas 13, 29-49.

Girón Alconchel, José Luis (2016a): “La segmentación lingüística del discurso en la prosa de la segunda mitad del siglo XVII”, en: Marta Fernández Alcaide/Elena Leal Abad/Álvaro S. Octavio de Toledo (eds.), 215-232.

Girón Alconchel, José Luis (2016b): “La segmentación del discurso historiográfico. De Solís (1686) a Bacallar (¿1726?)”, en: Araceli López Serena/Antonio Narbona Jiménez/Santiago del Rey Quesada (dirs.), El español a través del tiempo. Estudios ofrecidos a Rafael Cano Aguilar, t. 2, Sevilla, Universidad de Sevilla, 933-955.

Gómez de Enterría, Josefa/Martí Sánchez, Manuel (2016): “Rasgos discursivos en dos momentos de la medicina dieciochesca”, en: Marta Fernández Alcaide/Elena Leal Abad/Álvaro S. Octavio de Toledo (eds.), 281-298.

Gutiérrez Cuadrado, Juan (1988): “El latín, sustituido por el castellano en la universidad española: siglos XVIII-XIX”, en: Manuel Ariza/Antonio Salvador/Antonio Viudas (eds.), Actas del I Congreso Internacional de Historia de la Lengua Española, t. 2, Madrid, Arco Libros, 1205-1214.

Kabatek, Johannes (ed.) (2016): Lingüística de corpus y lingüística histórica iberorrománica. Con la colaboración de Carlota de Benito Moreno, Berlin/Boston, De Gruyter. 
Kamen, Henry (1981 [1979]): La España de Carlos II, Barcelona, Crítica.

Kamen, Henry (1997): “From decline to enlightenment: Spain 1675-1752”, en: Jesús Pérez

Magallón (ed.), "Del Barroco a la llustración”. Actas del Simposio celebrado en McGill University, Montreal, 2 y 3 de octubre de 1996 (Anejos de Dieciocho), Charlottesville (VA), The University of Virginia, 11-19.

Lapesa, Rafael (1966/1967): “Ideas y palabras: del vocabulario de la llustración al de los primeros liberales", en: Asclepio 18/19, 189-218.

Lapesa, Rafael (2000): Estudios de morfosintaxis histórica del español (ed. de Mํㅡ. T. Echenique y R. Cano), Madrid, Gredos.

López, François (1996): “Los novatores en la Europa de los sabios”, en: Studia historica. Historia moderna 14, 95-111.

López, François (1997): “La vida intelectual en la España de los novatores”, en: Jesús Pérez Magallón (ed.), "Del Barroco a la llustración”. Actas del Simposio celebrado en McGill University, Montreal, 2 y 3 de octubre de 1996 (Anejos de Dieciocho), Charlottesville (VA), The University of Virginia, 79-90.

López Piñero, José Ma (1979): Ciencia y técnica en la sociedad española de los siglos XVI y XVII, Barcelona, Labor.

López Piñero, José Ma (1993): “Juan de Cabriada y el movimiento novator de finales del siglo XVII. Reconsideración después de treinta años", en: Asclepio 45/1, 3-53.

López-Grigera, Ma Luisa (1982): “La prosa de Quevedo y los sistemas elocutivos de su época”, en: James Iffland (ed.), Quevedo in Perspective. Eleven Essays for the Quadricentennial. Proceedings from the Boston Quevedo Symposium: October 1980, Newark (Delaware), Juan de la Cuesta, 81-99.

Maravall, José Antonio (1978): “Novatores y pre-ilustrados: la obra de Gutiérrez de los Ríos, tercer conde de Fernán Núñez”, en: Cuadernos Hispanoamericanos 340, 15-30.

Martínez Ortega, M ${ }^{\mathrm{a}}$ de los Ángeles (1999): La lengua de los siglos XVI y XVII a través de los textos jurídicos. Los pleitos civiles de la escribanía de Alonso Rodríguez, Valladolid, Universidad de Valladolid.

Méndez García De Paredes, Elena (2008): “En los comienzos del discurso informativo: los Avisos de José Pellicer de Tovar (1639-1644)”, en: Concepción Company Company/José G. Moreno de Alba (eds.), Actas del VII Congreso Internacional de Historia de la Lengua Española, t. 2, Madrid, Arco Libros, 1949-1968.

Menéndez Pidal, Ramón ( $\left.{ }^{8} 1976\right)$ : Orígenes del español, Madrid, Espasa-Calpe.

Menéndez Pidal, Ramón (1991 [1986]): La lengua castellana en el siglo XVII, Madrid, EspasaCalpe.

Mestre Sanchís, Antonio (1996): “Los novatores como etapa histórica”, en: Studia historica. Historia moderna 14, 11-13.

Mestre Sanchís, Antonio (1998): “La aportación cultural de los novatores", en: Torre de los Lujanes. Boletín de la Real Sociedad Económica Matritense de Amigos del País 37, 99-118.

Muñoz Garrigós, José (1993): “Conflictos de normas en el primer tercio del siglo XVII”, en: Anuario de Lingüística Hispánica 9, 151-163.

Octavio de Toledo y Huerta, Álvaro S. (2007): “Un rasgo sintáctico del primer español moderno (ca. 1675-1825): las relaciones interoracionales con ínterin (que)”, en: Marta Fernández Alcaide/Araceli López Serena (eds.), Cuatrocientos años de la lengua del Quijote: estudios de historiografía lingüística e historia de la lengua española, Sevilla, Universidad de Sevilla, 421-442. 
Octavio de Toledo y Huerta, Álvaro S. (2008): “Un nuevo esquema adversativo en el primer español moderno (h. 1675-1825)”, en: Concepción Company Company/José G. Moreno de Alba (eds.), Actas del VII Congreso Internacional de Historia de la Lengua Española, t. 1, Madrid, Arco Libros, 877-907.

Octavio de Toledo y Huerta, Álvaro S. (2016): "Aprovechamiento del CORDE para el estudio sintáctico del primer español moderno (ca. 1675-1825)”, en: Johannes Kabatek (ed.), Lingüística de corpus y lingüística histórica iberorrománica. Con la colaboración de Carlota de Benito Moreno, Berlin/Boston, De Gruyter, 57-89.

Oesterreicher, Wulf (2008): “Configuraciones actanciales - variedades lingüísticas - tradiciones discursivas (siglos XVI-XVII)”, en Concepción Company Company/José G. Moreno de Alba (eds.), Actas del VII Congreso Internacional de Historia de la Lengua Española, t. 2, Madrid, Arco Libros, 2043-2064.

Pérez Magallón, Jesús (2002): Construyendo la modernidad: la cultura española en el "tiempo de los novatores" (1675-1725), Madrid, CSIC.

Porcar Miralles, Margarita (2012): “La construcción del discurso científico: ‘a propósito’ de las operaciones discursivas”, en: Emilio Montero Cartelle (ed.), Actas del VIII Congreso Internacional de Historia de la Lengua Española, t. 1, Santiago, Meubook, 247-261.

Vàrvaro, Alberto (1972/1973): "Storia della lingua: passato e prospettive di una categoria controversa”, en: Romance Philology 26/1, 16-51; 26/3, 509-531. 